\title{
Acute demyelination with leukoencephalopathy and cerebellar involvement in vitamin B12 deficiency
}

Desmielinização aguda com leucoencefalopatia e envolvimento cerebelar na deficiência de vitamina B12

Felipe Torres Pacheco', Thiago Luiz Pereira Donoso Scoppetta ${ }^{1}$, Monica Sznirer ${ }^{2}$, Roberto Antônio Paes², Antônio Jose da Rocha ${ }^{1}$

A 49-year-old woman presented with progressive ascending quadriparesis associated with paresthesias and recent wide-based gait. Cognitive impairment associated with reduced vibration and proprioception sense was observed. Brain MRI documented the presence of extensive white matter demyelination (Figure 1). Megaloblastic anemia, low B12 level and chronic gastritis were confirmed (Figure 2).

Vitamin B12 acts as a coenzyme in the methylmalonylCoA mutase reaction, essential for myelin biosynthesis ${ }^{1}$. This vitamin deficiency may result in a variable neurologic presentation ${ }^{1,2}$, including spinal cord, brain and cerebellar involvement. Our report supports the importance of performing diffusion and intravenous contrast administration to evaluate MRI evidence of acute demyelination in this setting.
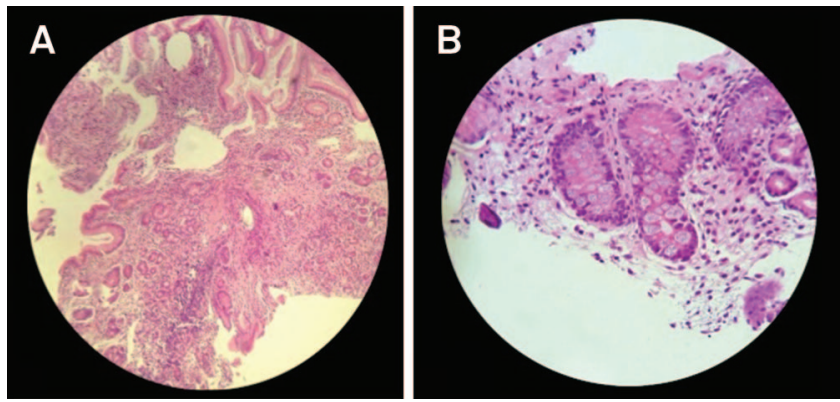

Figure 2. (A and B) Endoscopic biopsy illustrating the presence of chronic gastritis with intestinal metaplasia.
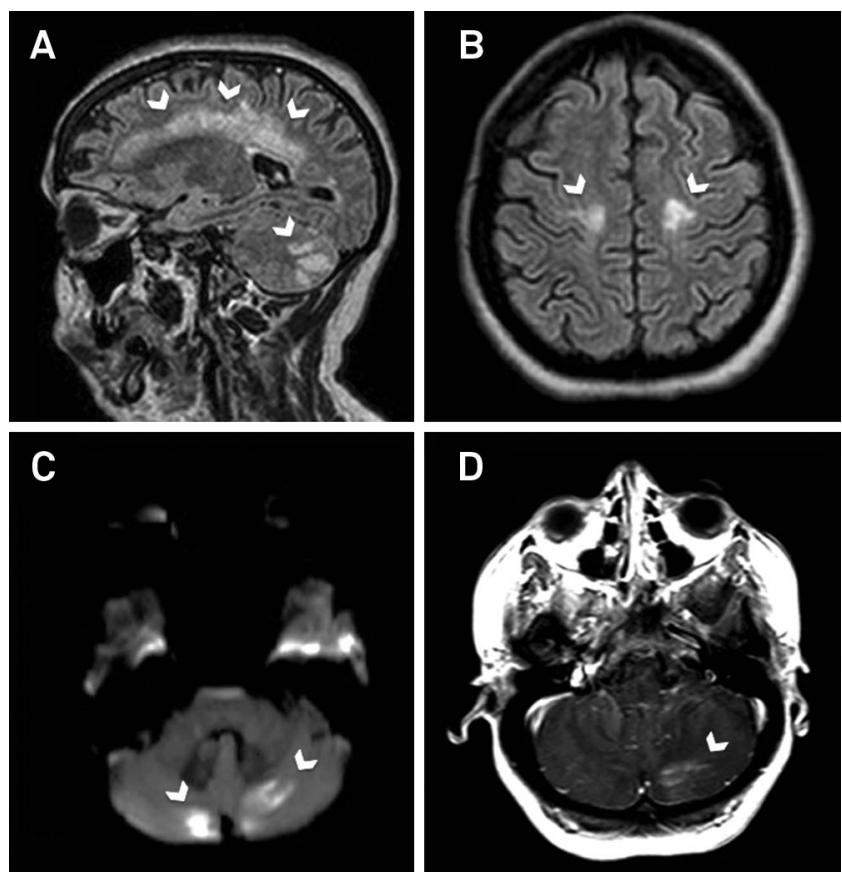

Figure 1. (A) FLAIR images demonstrated signal hyperintensity in the supra- and infratentorial white matter, (B) which was restricted to the corticospinal tracts in the subcortical precentral gyri. (C) Restricted diffusion was only observed in the cerebellum, (D) consistent with the patient's recent cerebellar symptoms and associated with gadolinium enhancement.
1. Stabler SP. Vitamin B12 deficiency. N Engl J Med. 2013;368(2):149-60 http://dx.doi.org/10.1056/NEJMcp1113996
Tangney CC, Aggarwal NT, Li H, Wils9on RS, Decarli C, Evans DA et al. Vitamin B12, cognition, and brain MRI measures: a cross-sectional examination. Neurology. 2011;77(13):1276-82. http://dx.doi.org/10.1212/ WNL.0b013e3182315a33

${ }^{1}$ Santa Casa de São Paulo, Faculdade de Ciências Médicas, Divisão de Neuroradiologia, Sao Paulo SP, Brazil;

${ }^{2}$ Santa Casa de São Paulo, Faculdade de Ciências Médicas, Divisão de Patologia, Sao Paulo SP, Brazil.

Correspondence: Felipe Torres Pacheco; Rua Doutor Cesário Motta Junior, 112; 01221-020 São Paulo SP, Brasil; E-mail: felipetorrespacheco@hotmail.com Conflict of interest: There is no conflict of interest to declare.

Received 25 November 2014; Accepted 16 December 2014. 